\title{
Resimli Bir Onyedinci Yüzyıl Osmanlı Mecmuası
}

\section{An Illustrated Seventeenth Century Ottoman Mecmua}

\author{
Melis Taner ${ }^{1}$
}

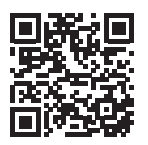

'(Dr. Öğr. Üyesi), Özyeğin Üniversitesi, Mimarlık ve Tasarım Fakültesi, İstanbul, Türkiye

ORCID: M.T. 0000-0002-5359-9489

Sorumlu yazar/Corresponding author: Melis Taner,

Özyeğin Üniversitesi, Mimarlık ve Tasarım Fakültesi,

Istanbul, Türkiye

E-posta:melistt@gmaail.com

Başvuru/Submitted: 02.03 .2021

Kabul/Accepted: 01.05.2021

Online Yayın/Published Online: 30.06.2021

Atıf/Citation: Taner, Melis. "Resimli Bir Onyedinci Yüzyıl Osmanlı Mecmuası". Sanat Tarihi YıllığıJournal of Art History 30 (2021), 169-185. https://doi.org/10.26650/sty.2021.889757

\section{öz}

Bu makale 1640-1642 yılları arasında Ahmed bin Musa isimli bir şahıs tarafından hazırlanan bir mecmuada (Berlin Devlet Kütüphanesi MS. Quart, 1988) bulunan IV. Murad'ın Bağdat kuşatmasına ait bir minyatürü inceler. Bu onyedinci yüzyıla ait olan mecmua çok özenli bir şekilde hazırlanmıştır. Mensur eserler metnin ana kısmında, manzum eserler, tarihler ve listeler ise haşiye kısmındadır. Mecmuanın bu organizasyonu eserin başındaki fihristte de belirtilir ve mizanpaj açışından, metnin tek bir elden çıkmasından, başlıkların ve bölüm başlarının yer yer dekoratif unsurlarla bezenmesinden ve özellikle de tek sayfa bir resmin dahil edilmesinden eserin çok özenli bir şekilde hazırlanmış olduğu anlaşılır. Mecmuada bulunan eserler pek çok farklı konuya aittir: mecmua dini konulu eserler ile başlar, daha sonra çeşitli tarihi eserler, hikayeler, şair tezkireleri, edebi eserler, tıp üzerine eserler, takvimler ve son olarak cifr hakkında eserler yer alır. Eserlerin pek çoğu onaltıncı ve onyedinci yüzyıllarda neşredilmiştir ve hepsi Türkçe'dir. Orijinali Arapça ya da Farsça olan birkaç eserin Türkçe çeviri ve adaptasyonları tercih edilmiştir. Eserin içeriğinden kısaca bahsettikten sonra, bu makale özellikle Bağdat kuşatması hakkındaki metin ve resim üzerinde durur. Metin kuşatma sırasında mevcut olan bir iç oğlanın payitahta gönderdiği bir mektuptur ve bu mektubun sonunda, mecmuayı hazırlayan Ahmed bin Musa sayfanın öteki yanında olan resme bakılmasına salık verir. Mecmua bir bütün olarak incelendiğinde çağdaşlarıyla bir takım benzerlikler gösterse de bu özenli resim ile birlikte diğerlerinden ayrılır.

Anahtar kelimeler: Mecmua, Erken Modern, Osmanlı, Mizanpaj, Resim, Bağdat

\section{ABSTRACT}

This paper discusses a compilation organized and compiled by Ahmed bin Musa between 1640 and 1642, focusing on a painting of the conquest of Baghdad (1638). The elegant and carefully prepared compilation uses both the text frame and the margin spaces. Prose texts are in the main text block, and verse texts, chronograms, and lists fill the margins, written in diagonals. Through its careful organization, decorative aspects, section headings, diagrams included in the final section, and the full-page painting, this compilation differentiates from its contemporaries in its fineness and elegance, which the compiler himself notes. After a brief introduction to the compilation and its content, this paper focuses on the letter from a court page who participated in Baghdad's conquest and the accompanying painting. The letter accompanies a carefully executed painting of the conquest of Baghdad, which distinguishes this compilation from most of its contemporaries.

Keywords: Compilation, Early Modern, Ottoman, Layout, Painting, Baghdad 


\section{EXTENDED ABSTRACT}

This paper discusses a compilation organized and compiled by Ahmed bin Musa between 1640 and 1642. It focuses specifically on a painting of the conquest of Baghdad (1638). The compiler emphasizes that this carefully prepared, elegant "mecmua" was written by one hand. The texts are organized in a way that uses both the text frame and the marginal spaces. Prose texts are in the main text block, and verse texts, chronograms, and lists fill the margins, written in diagonals. The mecmua begins with many religious works followed by various texts, including short stories, vernacularized scientific treatises, biographies of poets, and educating and moralistic works. Work on medicine, prognostication, and dating systems, some organized in tabular form appears at the end of the manuscript. Added to these are shortlists and chronograms on the margins.

The mecmua ends with an autobiographical section that reveals the selection process and preparation of materials chosen for the compilation. Through its careful organization, decorative aspects, section headings, diagrams included in the final section, and the full-page painting, this compilation differentiates from its contemporaries. Following a brief introduction to the compilation and its contents, this paper focuses on the letter sent by a court page who took part in the conquest of Baghdad and the accompanying painting. The letter accompanies a carefully executed painting of the conquest of Baghdad, which distinguishes this compilation from most of its contemporaries. This painting is introduced on the previous page with the words, "on the next page, the citadel, mosques, the river, the shrines of Imam Abu Hanifa and Imam Musa al-Kazim, and the tents of the Ottoman army surrounding the citadel are represented, may it be viewed."

The re-conquest of Baghdad under Murad IV was a significant victory for the Ottomans. The fascination with the attempts to retake Baghdad from the first quarter of the seventeenth century until its re-conquest in 1638, reflected in popular culture from the verses attributed to the seventeenth century minstrel Kayıkçı Kul Mustafa, the numerous letters included in compilations and manuals of correspondence, to accounts in contemporary chronicles. The painting in the mecmua depicts the Baghdad fort on the river bank with shrines on either side. The Shrine of Abu Hanifa at the bottom of the page (to the north of the fortress), and the shrines of the seventh Twelver Shii Imam Musa al-Kazim and the ninth Twelver Shii Imam Muhammad al-Jawad, are situated on the opposite river bank. Kuşlar Kal'ası, a smaller fortress, appears on this bank as well, past the makeshift bridge spanning the river. The fortresses depict solidity in their projecting bastions. Cannons surround the citadel, firing from all sides. Tents and lanterns are set up all around, as per the description. The addition of this finely executed, detailed, full-page painting testifies to the great importance that the compiler of this work attached to the re-conquest of Baghdad. Indeed, the manuscript also includes frequent references to Murad IV and the re-conquest elsewhere in the manuscript. Also notable, the marginal texts that pair with the re-conquest of Baghdad account relate to Ottoman-Safavid 
relations. Matching the beginning of the section relating to the letter sent from Baghdad, the marginal space contains an ornamental decoration and a title in red ink introducing the new section. It lists the gifts that the Safavid ambassadors brought to the Ottoman court during the reigns of Murad IV and Ibrahim I. For example, in August/September 1638, the Safavid ruler Shah Safi I's (r. 1629-42) envoy, Maksud, brought precious gifts such as textiles and Chinese porcelain. In July of 1641, the Safavid envoy Ibrahim Khan came bearing a letter from Shah Safi and numerous gifts. Furthermore, the thumbpieces in these several pages contain snippets of information about those who joined the Baghdad campaign, as well as those who died during the reign of Murad IV. These little notes in the margins, among which we also find Ahmed bin Musa's observations, reflect the voice of the compiler. 


\section{Giriş}

Bu makalede Berlin Devlet Kütüphanesi'nde korunan, onyedinci yüzyıl ortasında hazırlanmış bir mecmuada (Staatsbibliothek zu Berlin MS. Quart, 1988) bulunan ve Bağdat'1n IV. Murad döneminde (1623-40) Safeviler'den geri alınışını gösteren bir resim incelenir. Ahmed bin Musa isimli bir şahıs tarafından hazırlanan bu mecmua çeşitli akademik çalışmaların konusu olmuştur. ${ }^{1}$ Bu çalışmalar çoğunlukla edebiyat tarihi açısından değerli kazanımlar yapmış ve yalnızca bu mecmuada bulunan bir takım biricik eserleri gün yüzüne çıkarmışlardır. Bu çalışmaların dışında Cemal Kafadar bu onyedinci yüzyıl mecmuasına bütünsel bir şekilde yaklaşmış ve "çelebiler ve mecmualar" çağı olarak adlandırıldığ 1 dönem içinde, tarihsel bağlamında incelemiştir. ${ }^{2}$ Bu makalede ise Ahmed bin Musa'nın mecmuası sanat tarihi bakış açısı ile materyal bir obje olarak ele alınacak ve özellikle de içinde bulunan Bağdat resmi değerlendirilecektir. Hazırlanımına ve mizanpajına oldukça dikkat edilen bu mecmua bu özenli resim ile dönemindeki diğer örneklerinden ayrılır. ${ }^{3}$

\section{Mecmuanın İçeriği}

Berlin Devlet Kütüphanesi'nde bulunan bu mecmua 1640 ile 1642 yılları arasında hazırlanmıştır ve çeşitli uzunluklarda kırkı aşkın eseri kapsar. Mecmuanın içeriği hakkında Berlin Devlet Kütüphanesi'nde bulunan eserlerin kataloğunu hazırlayan Hanna Sohrweide detaylı

1 Edith Ambros, "An Ottoman Laṭ̂fe of the 16 $6^{\text {th }}$ Century," Osmanlı Araştırmaları 11 (1991): 25-34; idem, "The Image in the $16^{\text {th }}$ Century of Representatives of Science and Technology: Cameos by the Ottoman Poet Fakîrî," Proceedings of the XIIth Congress of the Comité International d'Études Pré-Ottomanes et Ottomanes (Prague: Archív Orientální, 1996): 17-28; idem, "The Letâif of Fakiri: Ottoman Poet of the $16^{\text {th }}$ Century," Wiener Zeitschrift für die Kunde des Morgenlandes 80 (1990): 59-78; idem, "Six Lampoons out of Fakîrî's Risâle-i Ta rifât," Wiener Zeitschrift für die Kunde des Morgenlandes 82 (1992): 27-36; Ahmet Naim Çiçekler, Esma Baralı Çiçekler, "Berlin Devlet Kütüphanesinde Bulunan XVII. Yüzyıla Ait Bir Mecmuadaki Türk Atasözleri Derlemesi," Dil ve Edebiyat Araştırmaları 18 (2018): 341-56; Şener Demirel, “16. Yüzyıl Divan Şairlerinden Tatavlalı Mahremî ve Şütürnâmesi," Milli Folklor 9/65 (2005): 49-66.

2 Cemal Kafadar, "Sohbete Çelebi, Çelebiye Mecmûa,” Mecmûa: Osmanlı Edebiyatının Kırkambarı, haz. Hatice Aynur (İstanbul: Turkuaz Yayınları, 2012), 45-52, 25.

3 Mizanpajın bu şekilde metin bölümü ve haşiye olarak ayrılması istisnai değildir. Timurlu şehzade İskender Sultan (ö. 1415) için hazırlanan antolojiler de bu metodu kullanır ve belki de en meşhur örneklerdir. Bu antolojiler için bkz. David Roxburgh, "The Aesthetics of Aggregation: Persian Anthologies of the Fifteenth Century," Islamic Art and Literature, haz. Oleg Grabar ve Cynthia Robinson (Princeton: Markus Wiener, 2001), 119-142. Bu Timurlu dönemi örneklerin dışında bir takım resimsiz Osmanlı eserleri de (özellikle tek bir eser ve şerhi) veya mecmualar (mesela Bibliothèque Nationale de France, Paris (Turc 78)) bu şekilde organize edilmiştir. Berlin Devlet Kütüphanesi'ndeki örnekle neredeyse çağdaş bir Safevi mecmuası da bu şekilde organize edilmiştir. Samet Budak tarafindan dikkatime getirilen bu örnek Tehran Üniversitesi Kütüphanesi’ndedir (MS 2591). Mirza Mu 'ina mecmuayı bir araya getirmiştir ve bu mecmua Muhammad Sadiq isimli bir şahsın yazdığı giriş bölümü ile başlar. Pek çok farklı kaynaktan oluşan bu mecmuanın içinde inşa örnekleri, hükümler, şiirler, ufak bir seyahatname ve tarihler vardır. Bu mecmuanın da (1zgara şeklinde organize edilmiş) bir fihristi vardır. Bu mecmuada da bir takım şemalar vardır. Ancak Berlin mecmuasından farklı olarak Tehran mecmuası tek bir elden çıkmamıştır ve daha düzenli olarak başlayan Tehran mecmuası daha sonra farklı ellerin de eklemlemelerini gösterir. $\mathrm{Bu}$ mecmua ile ilgili bkz. Mansur Sefatgol, "Majmū'ah'hä: Important and unknown sources of historiography of Iran during the last Safavids - the case of the Majmū 'ah-i Mìrzā Mu 'ìnā," Persian Documents: Social History of Iran in the Fifteenth to Nineteenth Centuries, haz., Nobuaki Kondo (Londra: Routledge, 2003), 73-85. 
bilgiler verir. ${ }^{4} \mathrm{Bu}$ nedenle bu makalenin konusu olan resmi incelemeden evvel mecmuanın içeriğine yalnızca kısaca değinilecektir. 526 varaktan oluşan bu eser, şemseli, salbekli ve köşebentli bir deri cilt içindedir. Restorasyon görmüş bu eserde eksik birkaç varak tespit edilmiştir. ${ }^{5}$ Eser tek bir elden, nesih hatla yazılmıştır. ${ }^{6}$ Eserlerin başlıkları çoğunlukla kırmızı, nadiren mavi mürekkeple belirtilmiştir ve başlıklara, eseri hazırlayan Ahmed bin Musa ara sıra kendi notlarını eklemiştir. ${ }^{7}$

Mecmuanın başında bir fihrist vardır ve bu fihrist okuyucuya mecmuanın organizasyonu hakkında fikir verir. Fihristin bir sayfası manzum, diğer sayfası mensur eserlere ayrılmıştır. Mecmuadaki sayfa düzeni de bu şekildedir ve metin kısmında mensur eserler, haşiyede ise manzum eserler ile kısa metinler ve listeler yer alır. Mecmuanın başlangıcından itibaren okuyucuya mecmuanın organizasyonu ile ilgili bir fikir verilmiştir bu şekilde. Sayfa düzeninin manzum ve mensur eserlere göre organize edilmesinin ötesinde eserlerin başlangıç ve bitiş noktalarının da uyumlu olmasına çalışılmıştır. Yani bir mensur eser biter ve yenisi başlarken, çoğunlukla haşiyede olan metin de biter ve yenisi başlar. Ayrıca konuları itibariyle de yer yer benzerlikler gözlemlenebilinir.

Mecmuada öncelikle dini konulu eserlere yer verilir. Bunların pek çoğu dualar, hacc sırasında yapılması gerekenler, Allah'ın isimleri, hadis çevirileri ve Hz. Muhammed'in hayatı hakkındadır. ${ }^{8}$ Daha sonra Yūsuf u Züleyhāa, Şāh u Gedā, Gencine-i Rāz gibi hikayeler ile Nev'i’nin bilimler üzerine popüler eseri Netāyicü'l Fünūn'u, Riyazi'nin şairler tezkiresi ve tarih üzerine çeşitli eserler yer alır. ${ }^{9}$ Mecmuanın sonlarına doğru tıp hakkında kısa birkaç risale, atasözleri, kronogramlar, takvimler ve ahret bilimi üzerine eserler mevcuttur. ${ }^{10}$ Son olarak

4 Hanna Sohrweide, Türkische Handschriften, Teil 5 (Verzeichnis der Orientalishchen Handschriften in Deutschland) (Wiesbaden: Franz Steiner Verlag, 1981), 30-4.

5 212a-264a varakları arasında asıl metin kısmında olan Riyāzi'nin tezkiresi Riyāzü ’şŞu 'arā eserinde eksik bir kısım vardır ve "ra" harfinin bir kısmı (v. 241) ile "ta" harfine kadar olan bölüm eksiktir.

6 Eserin tek bir elden yazılmış olması eserin son kısmında özellikle belirtilmiştir. Bu bölümde mecmuayı hazırlayan Ahmed bin Musa projeye nasıl başladığını, nasıl Anadolu kazaskeri küttabından Cildi Çelebi ile ortak olduğunu anlatır (varak 523a). Cemal Kafadar bu son bölüme odaklanarak bu mecmuanın önemini gözler önüne serer. Kafadar mecmualar üzerine olan çalışmalarına devam etmektedir. Kafadar, "Sohbete Çelebi, Çelebiye Mecmûa," 212 .

7 Örneğin Şāh u Gedā adlı eseri şu şekilde tanıtır, “Bu dahi Gencine-i Rāz șāḥibi Taşlı Yaḥyā’nıñ Şāh u Gedāsı'dır ki burāya münāsıb olmaġla tahrīr olunur.” Ahmed bin Musa'nın dediği gibi, haşiyede olan bu eser, mecmuada Gencine-i Rāz'ı takip eder. MS Or. Quart 1988, $213 \mathrm{a}$.

8 Bunların arasında şeyhülislam Ebusu 'ud'un (ö. 1574) Du 'anāme'si, İlyas Çelebi ibn 'İsa'nın (ö. 1559/60) Esmā-i Hüsna şerhi, Hakani'nin (ö. 1606/7) Hilye-i Şerîf'i, Latifi'nin (ö. yaklaşık 1582) Șubhātü’l 'Uşşāḳ'1, Veysi'nin Dürretü’t Tāc'ını sayabiliriz. Ayrıca mecmuayı hazırlayan Ahmed bin Musa'nın Fenari'ye (ö. 1431) atfettiği Şurūt-u Șalāt isimli eser ile bir de yazarının kim olduğu açık olmayan (ancak Ahmed bin Musa'nın Sinan Efendi’ye atfettiği) Menāsik-i Hacc isimli eser bulunur.

9 Dini konulu eserlerden sonra çeşitli türlerden eserler yer alır. Bunların içinde yukarıda bahsedildiği gibi bir takım mesneviler olduğu gibi, çeşitli hikayeler ve letaifler yer alır. Cinani'nin (ö. 1595) Bedayiü'l Āșār'1 ve bir takım başka hikayeleri, Lami i Çelebi'nin (ö. 1532) 'İbretnümā'sı yer alır. Ayrıca Ahmed Bican'ın 'Acā'ibü'l Mahlūkāt ve Dürr-ü Meknūn'undan seçmeler ile Gelibolulu Mustafa 'Ali'nin (ö. 1600) Fuṣūl-ü Hall u 'Akd'1 ve 'Ali Ekber Hitayi'nin (16. yüzyılda yaşamış) Hitaynāme'sinin Türkçe çevirisi mevcuttur.

10 Bunların arasında İmam Suyuti'ye atfedilen cifr, Zigetvari Ali Dede'nin cifr kasidesi, İbn 'İsa'nın Rumūz $u$ Künūz'u, Ahi Evran'ın Rumūz'unun Gülşehri tarafından çevirisi, Ni metullah'ın Mu 'amma-yı cifr-i cami 'kasidesi 
Yaratılışın başından Hicri 1050 (MS 1640/1) yılına gelene kadar olan olaylar ve geçen zaman belirtilmiştir. Eser, Kafadar'ın da özellikle üstünde durduğu şekilde Ahmed bin Musa'nın eserin yazılışı hakkında yazdığı kısım ile sona erer. ${ }^{11}$ Genel olarak incelendiğinde mecmuada özellikle Türkçe eserler ve Arapça ya da Farsça eserlerin Türkçe adaptasyonları seçilmiştir. ${ }^{12}$ Seçilen eserler çoğunlukla onaltıncı ve onyedinci yüzyıllarda neşredilmiş ve yaygınlıkla bulunan eserlerdir. Ayrıca, mecmuayı hazırlayan Ahmed bin Musa, Cevri Çelebi'nin (ö. 1654) 1635 tarihli Melhame'si gibi en güncel eserleri de mecmuasına eklemeye dikkat etmiştir. Eserin son kısımlarında, bedenin uzuvlarının seğirmesi ve anlamları ve takvim hesaplamaları hakkındaki bölümlerde özenle hazırlanmış, farklı noktaları farklı renk mürekkeplerle gösteren tablolar kullanılmıştır (resim 1). Ayrıca bu makalenin konusu olan ve yine aynı özenle çizilmiş bir Bağdat resmi de karşımıza çıkar (resim 2). Makalenin geri kalanında Bağdat'ın 1638'de IV. Murad zamanında Safeviler'den alınmasını anlatan metin ve resim üzerinde durulacaktır.

\section{İki Devlet Arasında Kalmış Bir Eyalet}

Onaltıncı yüzyılın başından onyedinci yüzyılın ilk yarısına kadar Bağdat eyaleti dönem dönem el değiştirmiştir. Safevi devletinin kurucusu Şah İsma 'il (h. 1501-1524) Bağdat'1 1508 yılında Akkoyunlu'lardan almıştır. Şi 'i İslam'ın savunucusu olan Şah İsma 'il, Bağdat'ı ele geçirince Bağdat'taki Ebu Hanife ve Abdülkadir Geylani türbeleri gibi önemli Sünni kutsal mekanları tahrip ettirmiştir. Yedinci Şi ' i imamı olan İmam Musa Kazım’ın türbesini yeniletmiş ve İmam Ali'nin (Necef'teki) ve İmam Hüseyin'in (Kerbela'daki) türbelerine şamdanlar ve halılar tahsis etmiştir. Bağdat daha sonra 1534 yılında Osmanlılar'ın kontrolü altına girmiştir. Tahrip edilen Sünni yapılar Kanuni Sultan Süleyman döneminde (1520-1566) yeniden düzenlenmiştir.

1578-1590 yılları boyunca Osmanlılar ile Safeviler yeniden savaşta iken iki devlet arasında kalan topraklar sıklıkla çatışmaların merkezi olmuştur. ${ }^{13} 1570$ 'lerin başlarından itibaren aslında gerilimin mevcut olduğu Bağdat valilerine giden çeşitli emirlerden anlaşılabilir. ${ }^{14}$ Bölgenin güvenliğinin korunması için valilere sıklıkla emirler gönderilir, özellikle de Amasya Antlaşması'nın (1555) koşullarını aşmamaları hakkında uyarılırlar. ${ }^{15}$ On iki yıl süren savaş sonunda Osmanlılar ve Safeviler anlaşırlar; şartlar Osmanlılar'ın lehindedir. Ancak sınır bölgesinde gerilim onyedinci yüzyılın başlarında yeniden artar.

çevirisi vardır. Ayrıca Kaysunizade'nin Kitābü'l Ṭıbb’ı ve muhtemelen Uzun Firdevsi'nin Pendname'si yer alır. Mecmuayı organize eden Ahmed bin Musa çeviri metinlerin bir kısmında eseri kimin çevirdiğini belirtir, ancak bu bahsi geçen bölümlerde çeviren kişinin ismi belirtilmemiştir.

11 Kafadar, "Sohbete Çelebi, Çelebiye Mecmûa," 48-49.

12 Örnek olarak Latifi'nin (ö. yaklaşık1582) Subhātü'l 'Uşşāḳ’1 (hadisler tercümesi), Hamdi'nin (ö. 1503) Yusuf ve Züleyha'sını veya Ahi'nin (ö. 1517) Hüsn u Dil'ini verebiliriz.

13 Osmanlı-Safevi ilişkileri hakkında bkz. Bekir Kütükoğlu, Osmanlı-Iran Siyasi Münasebetleri (1578-1612) (İstanbul: İstanbul Fetih Cemiyeti, 1993).

14 Melis Taner, "Caught in a Whirlwind: Painting in Ottoman Baghdad in the Late Sixteenth-Early Seventeenth Centuries" (Doktora Tezi, Harvard Üniversitesi, 2016), 38.

15 Colin Imber, "The Persecution of the Ottoman Shi 'ites According to the Mühimme Defterleri, 1565-1585," Der Islam, 2/3 (1979), 248. 
Onyedinci yüzyılın ilk çeyreğinde, Osmanlı İmparatorluğu genelinde yaşanan ekonomik problemler ve ayaklanmalardan ${ }^{16}$ da faydalanarak eyaletin kontrolünü ele geçiren Bekir Subaş1, eyaletin Safeviler'in kontrolüne geçmesine sebep olur. Yeniçeri ocağı mensubu olan Bekir Subaşı, bu karışıklık ortamında hayli güç kazanmış, hatta neredeyse Bağdat'ın hakimi haline gelmişti. Onyedinci yüzyıl ortalarında yaşayan Bağdatlı yazar Mustafa bin Molla Rıdvan'ın anlattığı üzere Bağdat halkı atanan valilerin gazabından çektiklerini söyleyerek Bekir Subaşı'nın onları korumasını istediklerini iletirler. ${ }^{17}$ Özellikle 1619-20 yıllarındaki yerel ayaklanmalar, kıtlık ve Bağdat'taki ekonomik problemler Bekir Subaşı'nın fiili hakimiyet ilan etmesiyle ilişkilendirilir. ${ }^{18}$ Bağdat ve civarındaki yerel güçler dönem dönem bu coğrafyanın sınır bölgesi olmasından dolayı Osmanlılar ile Safeviler'i birbirlerine karşı kullanarak kendi güçlerini arttırmaya çalışmışlardır. Bekir Subaşı da benzer bir şekilde, daha sonra pişman olsa da (Mustafa bin Molla Rıdvan'ın anlatımına göre), ${ }^{19}$ eyaletin Safeviler'in eline geçmesine sebep olacaktı. ${ }^{20} 1623$ yılında Bağdat'1 kuşatan Şah Abbas I (h. 1588-1629) şehri ele geçirir. 1625-26 yıllarında Hafız Ahmed Paşa (ö. 1632) Bağdat'ı geri almaya çalışsa da başarılı olamaz. ${ }^{21} 1629-30$ yılında yeniden muhasara edilse yine başarılı olunmaz ve eyalet 1638 yılına kadar Safeviler'in elinde kalır. ${ }^{22}$ Berlin mecmuasında mevcut olan bir mektup IV. Murad'ın 1638 seferini anlatır.

\section{Bağdat Seferi ve "Hazine Oğlanlarından Bir İç Oğlanın Mahmiye-yi İstanbul'a Gönderdikleri Mektup"}

Ahmed bin Musa'nın mecmuasında 377b-381a sayfaları arasında, ana metin kısmında bulunan bir mektup sureti 1638 seferini anlatır ve bu mektubun ardından tam sayfa Bağdat resmi yer alır. Bu mektuptan önce mecmuada bir kadı ile bir hırsız arasında geçen hikaye yer alır. Dekoratif bir bant bu hikaye ile kırmızı mürekkeple yazılmış yeni bölümü ayırır. Bu

16 Naẓmīzāde Murtaża, Gülşen-i Hulefā: Băğdat Tarihi 762-1717, haz. Mehmed Karataş (Ankara: Türk Tarih Kurumu Yayınları, 2014), 195, 201; Mustafa Akdă̆, Celali Isyanlarl (1550-1603) (Ankara: Ankara Üniversitesi Basım Evi, 1963); Şevket Pamuk, "The Price Revolution in the Ottoman Empire Reconsidered," International Journal of Middle East Studies 33 (2001), 69-89.

17 Mustafa b. Molla Rıdvan'ın anlattığı üzere, özellikle vali Dilaver Paşa’nın (ö. 1622) zorbalıklarından şikayet eden halk Bekir Subaşına, "Sen bizim serdār-ı leşkerimiz olub bizi ḥıž u ḥırāsetiñe aldıkdan șoñra gelen beglerbegilere vücūd virmiyelim," derler. Muștafa b. Mulla Rıḍvan el-Bag̉dādī, Tārīh-i Fetihnnāme-i Bag̀dād, Bodleian Or. 276, 75b; Melis Taner, Caught in a Whirlwind: A Cultural History of Ottoman Baghdad as Reflected in its Illustrated Manuscripts (Leiden: Brill, 2020), 18.

18 Mușțafa b. Mulla Rı̣̣van el-Bag̉dādī, Tārīh-i Fetiḥnāme-i Bag̉dād, Bodleian Or. 276, 88a; Naẓmīzāde Murtaża, Gülşen-i Hulefā: Băğdat Tarihi 762-1717, 201.

19 "Bekir Paşa bu ḩaber-i şena at eșeri istima' eylediḳde naire-yi ġażābı işti āl bulub dūd-u gażābını cigerinden dimāg̀ı saḳfına șu 'ud eyledi. Zirā Sünni Müslüman Ḥanefi'ül mežheb idi. Egerçi bu hușuṣda günahı yog̉idi velekin dini ḳavi ve mezhhebi üzre muḥkem idi.” Mușțafa b. Mulla Rı̣̣van el-Baġdādī, Tārīh-i Fetiḥnāme-i Bajgād, Bodleian Or. 276, $125 \mathrm{~b}$.

20 Taner, Caught in a Whirlwind, 35.

21 Bu seferde bulunan bir turnacıbaşının gönderdiği mektup hakkında bkz. Claudia Römer, "Die Osmanische Belagerung Bagdads 1034-35/1624-25, Ein Augenzeugenbericht,” Der Islam 66 (1989), 119-136.

22 Rhoads Murphy, Ottoman Warfare, 1500-1700 (Londra: UCL Press, 1999), 115-122. 
yeni bölümün başlığı şu şekildedir: "Sulțan Murad bin Aḥmed ḥażretleri sene 1048 tarihinde 'asker-i bī-şümar ile Bag̉dad'a varub sa 'adetle fetḥ eyledikde hazine og̉lanlarından bir iç og̉lanıñ maḥmiyye-yi İstanbul'a gönderdikleri mektubuñ șuretidir.” Aynı sayfanın haşiye kısmında, neredeyse bu bölümle aynı yere denk gelecek şekilde, yeni bir metin başlar (resim 3). Bu kısım ise bu dönem Safevi elçisinden gelen hediyeleri listeler, yani konu olarak metin kısmında bulunan mektup ile haşiye kısmında bulunan metin arasında hem mizanpaj açısından hem de konu açısından yakınlık vardır.

Ana metin kısmında mevcut olan mektup, Ahmed bin Musa'nın başlığında belirttiği üzere sefere katılan bir iç oğlanın seferle ilgili gözlemlerini anlatan bir metindir. Bağdat topraklarını "rayiḥa-yı rafażadan yıḳayub pāk itmek niyetiyle" (varak 377b) Musul'dan yola çıktıklarını belirtir. 1048 senesinin Receb ayının yedinci gününde (14 Kasım 1638) Bağdat'a varırlar (varak 378a). İmam Ebu Hanife'nin türbesinin de olduğu bölgede otaklarını kurarlar ve kaleyi çevrelerler. Balyemez toplarla kalenin Ak Kapı tarafından saldırmaya başlarlar. Mektubun yazarı mektubun başından beri mecazi bir dil kullanarak savaşı anlatır, balyemez topları kuyruğunu yere vuran, ağzından ateş fişkırtan ejderhalara benzetir, kalenin "zehr-ālud cesed gibi șapır șapır dökülmege” başladığını söyler (varak 378b). Ancak kaleyi çevreleyen hendekleri geçmenin zor olduğunu ve savaşın bir süre burada devam ettiğini belirtir. Sonunda otuz sekizinci gün kale dibine varırlar ve savaş kale içinde devam eder. Savaşı yine mecazi bir dille şöyle anlatır: "bu ceng öyle bir ceng oldu ki kuştelerden puşteler yığılub hendekiñ içi ḳanıyla leşiyle țolub yine ādem ādem üstüne bașılub ḳulelere yürürlerdi. Ve'l hașıl bu cengiñ şiddet vașfını taḳdir eylemege zenabıñ tahammül olmaz" (varak 380b). Sonunda otuz dokuzuncu gün kaleyi ele geçirirler, vali Bektaş Han teslim olur. İç oğlanın uzun uzun anlattığ ve Osmanlılar'ın zaferini ön plana koyan mektubunun sonunda, mecmuayı hazırlayan Ahmed bin Musa'nın yazdığı tahmin olunan bir bölüm vardır ve kağıdın arka tarafında Bağdat ve camiileri ve türbelerinin, ayrıca Osmanlı askerlerinin otaklarının, top ve tüfenglerin, meşalelerin resimleri olduğu belirtilir. Hepsinin resmedildiğini söyler ve "nazar oluna" der (varak 381a). Ayrıca, Bağdat'ın fetih haberi İstanbul'a vardığında büyük bir heyecan olduğunu ve yirmi gün yirmi gece kutlama olduğunu belirtir. 1623'te Osmanlılar'ın Bağdat'1 kaybetmelerinin ardından çeşitli başarısız denemelerinden sonra 1638 yılında yeniden fethi Osmanlılar için önemli bir zafer olmuştu. Özellikle 1638 seferi pek çok farklı türde eserin konusu olmuştur. Dönem kronikleri ${ }^{23}$, arşiv belgeleri, ${ }^{24}$ inşa mecmualarındaki mektuplar, ${ }^{25}$ hatta şair Kayıkçı

23 İbrahim Peçevi, Peçevĩ Tārihi (İstanbul: Matbaa-i Amire, 1864); Nermin Yıldırım, "Karaçelebizade Abdülaziz Efendi'nin Zafername Adlı Eseri (Tarihçe-i Feth-i Revan ve Bağdad), Tahlil ve Metin” (Yüksek lisans tezi, Mimar Sinan Üniversitesi, 2005); Naima Mustafa Efendi, Tarih-i Naima hazırlayan Mehmet İpşirli, (Ankara: Türk Tarih Kurumu Yayınları, 2007).

24 Halil Sahillioğlu, “Dördüncü Murad'ın Bağdad Seferi Menzilnamesi,” Belgeler, 2/3-4 (1965), 1-39.

25 Britanya Kütüphanesi’nde Or. 3482 envanter numaralı inşa mecmuasında mevcut olan mektup 1626 yılındaki seferi ve o sırada askerlerin yaşadığı zorlukları ve zahire yetersizliğini anlatırken, mektubu yazan şahıs askerlerin dertlerinin türkülerde söylendiğinden bahseder (varak 277b). Benzer bir şekilde 1638 yilındaki sefer de pek çok halk şiirine ilham vermiştir. Ayrıca bkz. Anonim, Baġdād seferinde sa'adetlü pādişāhımızıñ iç og̀lanlarından bir iç og̉lanı merhum ḳılar ag்asına irsal eyledügi mektub șuretidir. Britanya Kütüphanesi Add. 9704, 1v-42r 
Kul Mustafa'ya atfedilen şiirler ${ }^{26}$ bu fethin önemini gösterir. Bu seferin Osmanlılar için önemi Ahmed bin Musa'nın mecmuasında bulunan bu mektuptan ve ayrıca çok özenli olarak yapılmış resimden de anlaşılabilir.

Sonraki sayfada Bağdat'ın resmi vardır. Resim tüm sayfayı kapsar ve Ahmed bin Musa'nın da aynen belirttiği gibi nehir kenarındaki kaleyi ve kalenin dört yanında kurulu çadırlar ile kaleye doğrultumuş, ateş eden topları gösterir. Kale burçlarıyla birlikte sağlam bir görüntü verir ve metinde de kalenin sağlamlığından bahsedilir. Ayrıca kalenin ve iç kalenin (nehrin yakasına yakın tarafta) içinde bulunan yapılar ve camiler ile Şeyh Sühreverdi'nin türbesi de resmedilmiştir. Kale nehir kenarındadır, nehri aşmak için hazırlanan köprü görülür. Bağdat kalesinin karşısında, nehrin öteki yakasında daha küçük, harap olmuş bir kale, Kuşlar Kalesi, de görülür. Ayrıca nehrin iki yakasında Bağdat’taki türbeleri görmek mümkündür. Kalenin kuzeyinde (resimde sayfanın altında solda) Ebu Hanife türbesi ve nehrin öteki yakasında İmam Musa el-Kazım ile İmam Muhammed el-Cevad'ın türbelerini görmek mümkündür (resmin sağ altında) (resim 4). Daha önce de bahsedildiği gibi Bağdat ve çevresi, özellikle Necef ve Kerbela, barındırdıkları önemli Sünni ve Şi i türbeler açısından hem Osmanlılar hem de Safeviler için önemli bir bölgeydi. Bu resimde de Bağdat'ın türbelerini, belirgin, uzun boyunlu, soğansı kubbeleriyle görmek ve ayırt edebilmek mümkündür.

Daha da belirgin olan ise kaleyi saran toplardır. Bütün toplar kaleye doğru yönelmiştir. Top ateşiyle çıkan dumanlar mavi renk ile belirtilmiştir ve nehrin mavisiyle uyumludur. Ayrıca kalenin etrafındaki hendekten de çıkan dumanları da görmek mümkündür; metinde ağızlarından ateş fişkırtan ejderhalara benzetilen top ateşleri bu şekilde görselleştirilmiştir. Metinde de nasıl askerlerin hendek kazarak oralardan da saldırmaya çalıştıklarını, nasıl Safevi ordusunun hendekleri doldurmaya çalıştıkları anlatılır. Osmanlı askerleri kalenin üç tarafını saran hendeklerden ve nehrin öte yakasından da top desteğiyle saldırırken, kalenin burçlarından da çıkan dumanları ve Safeviler'in saldırısını görmek mümkündür. Osmanlıları ve ordularını simgeleyen otaklar ve sancaklar ise kompozisyonun tümüne yayılmıştır ve tamamen kaleyi sarmıştır. ${ }^{27}$ Resmin tümüne ve kompozisyonuna baktığımız zaman anlaşılan odur ki Osmanlı ordusu kaleyi tamamen sarmıştır ve kalenin alınışı an meselesidir. Metin ne kadar zorluklardan bahsetse de mecazi bir dil ve detaylı bir anlatım ile otuz dokuz gün süren kuşatmayı gözler önüne getirir. Resim de metinle yakın bir ilişki içindedir ve detaylı bir şekilde şehir gösterilmiştir. Ahmed bin Musa'nın mektubun sonuna eklediği not da bu detayları yansıtır: Osmanlılar'ın otakları, meşaleler, toplar, hepsi resmedilmiştir. Resmi de acaba Ahmed bin Musa mı yapmıştır? Ya da eserin hazırlanmasında ona yardımcı olan, eseri kopyalan Cildi

ve Zarain Aga, A Relation of the Late Seidge and Taking of the City of Babylon by the Turke, (Londra, 1639).

26 Mehmet Fuat Köprülü, XVIIinci Asır Sazşairlerinden Kayıkçı Kul Mustafa ve Genç Osman Hikayesi (İstanbul: Evkaf Matbaası, 1930).

27 Osmanlı döneminde otak formasyonu hakkında bkz. Nurhan Atasoy, Otağ-ı Hümayun: Osmanlı Çadırları (İstanbul: Koç Kültür Sanat Yayınları, 2002). 
Çelebi'nin eli olabilir mi? ${ }^{28}$ Ahmed bin Musa bize bu konuda bilgi vermez, ancak metinle bu kadar yakın ilişkisi olan ve tüm mecmuada gösterilen özenin burada da görüldüğü resmin, mecmuanın hazırlanmasında parmağı olan Ahmed bin Musa ya da Cildi Çelebi'nin elinden çıkmış olabileceğini düşündürür. Resmi yapan her kimse, onaltıncı yüzyıl ortalarından beri yaygınlaşmakta olan ve mecmuanın hazırlandığı dönemde yerleşik hale gelen kent ve kuşatma resimleri çerçevesinde incelendiğinde bu mecmuadaki resmin tek bir bakış açısı kullanması itibariyle ne kadar ilginç olduğu anlaşılır.

Piri Reis'in (ö. 1554) kent ve liman haritaları ve özellikle de sınır bölgelerinin resmedilmesi açısından çok önemli bir kaynak olan Matrakçı Nasuh'un (ö. 1564) Beyan-ı Menazil-i Sefer-i 'Irakeyn isimli eseri Osmanlı resim geleneğinde şehir temsilleri açısından öncü olmuşlardır. ${ }^{29}$ Matrakçı Nasuh, Sultan Süleyman'ın 1534-36 yıllarındaki doğu seferine katılarak yol boyunca menzillerin resimlerini ve kısa tarihini aktarır bu eserinde. Eser, Sultan'ın İstanbul'dan yola çıkarak Maltepe, İznik, Kütahya, Konya, Sivas, Erzindan, Erzurum, Tebriz, Sultaniye, Hamadan ve oradan güneye doğru Necef ve sonra Bağdat'a geçişini takip eder. Matrakçı Nasuh bu menzillerin resimlerini de birbirini takip eder bir şekilde, sekanslar halinde eklemiştir. Menzillerin resimleri tek sayfayı kapladığı gibi bazen bir sayfada birkaç sahne halinde yukarıdan aşağıya, tıpkı bir menzilname gibi okunacak şekilde yerleştirilmiştir. Sınır bölgesindeki şehirler, özellikle Tebriz, Sultaniye ve Bağdat, diğer menzillere göre daha canlı tonlarla resmedilmiştir ve mimarileri daha detaylı incelenmiştir. Özellikle bu coğrafyadaki mimarinin farklılı̆̆ çinili ve konik kubbeleri ile dikkat çeker. ${ }^{30}$ Ayrıca hem Osmanlılar hem de Safeviler için büyük önem taşıyan türbeler ayrıca resmedilmiştir. Beyan-ı Menazil-i Sefer-i Irakeyn'de Bağdat' ın teshiriyle birlikle şahın "ḳavā id-i bāṭıla ve ḳavānīn-i 'ạṭlasın def" u ref'" edildiği, yerine "ḳā ide-i güzīide-i Sulțānīye" getirildiği belirtilir. ${ }^{31}$ Zaten eserin başlangıcında da benzer bir düşünce ile yola çıkıldı ğı belirtilir. Bu bağlamda hem payitahtın hem de elde edilen bu önemli şehirlerin detaylı temsili, hem de Bağdat civarındaki kutsal toprakların ayrı ayrı resmedilmesinin imparatorluğun merkezinden en uç sınırlarına kadar Sünni İslam’i ve siyasi kontrolü simgelediğini söylemek mümkün olur. Matrakçı Nasuh'un Bağdat tasviri çift sayfaya yayılmıştır ve düz bir hat olarak gösterilen nehir iki sayfayı görsel olarak birbirinden ayırır. Bu düzenli ayrımdan da anlaşılacağı üzere Matrakçı şehre ayrı bir düzen katmıştır. Çift sayfanın sağında dikdörtgen biçimli kale ve nehir yakasında olan iç kaleyi görmek mümkündür. Kuşbakışı yaklaştığımız şehirde burçları farklı açılardan, sanki cepheden bakıyor gibi görürüz; kalenin içindeki yapılar ise nehirden bakılıyor gibi yansıtılmıştır. Sayfanın sol tarafında, kalenin karşısındaki yapılar ise yine nehir tarafından gözlemleniyor gibi yansıtılmıştır. Matrakçı Nasuh şehrin ana detaylarını, yani kaleyi,

28 Bkz. Kafadar, "Sohbete Çelebi, Çelebiye Mecmûa," 49.

29 Osmanlı resim geleneğinde haritacılık ve şehir resimleri hakkında genel bir giriş için bkz. Serpil Bağc1, Filiz Çăgman et al., Osmanlı Resim Sanatı, (İstanbul, T.C. Kültür ve Turizm Bakanlığı, 2006), 68-82.

30 Kathryn A. Ebel, "City Views, Imperial Visions: Cartography and the Visual Culture of Urban Space in the Ottoman Empire, 1453-1603" (The University of Texas at Austin, 2002), 177.

31 Hüseyin Yurdaydın, Nașūhü's-Silāḥ̄ (Maṭrākçci)): Beyān-ı Menāzil-i Sefer-i 'Irākeyn-i Sulțān Süleymān Hāan), (Ankara: Türk Tarih Kurumu Basımevi, 1976), 213, 242. 
türbeleri, nehri aşan köprüyü yansıtır ve birkaç hayvan ve hurma ağaçları dışında — ki bunlar da şehre canlılık katar_ _şehir sadece ana öğeleriyle yansıtılmıştır.

Onaltıncı yüzyılın ikinci yarısında da pek çok resimli gazaname ve tarihlerde kuşatma sahneleri ve ayrıca arşivlerde bulunan bir takım kuşatma planları da mevcuttur. ${ }^{32}$ Bunların bir kısmı Matrakçı Nasuh'un oluşturduğu geleneği devam ettirir. Osmanlı arşivlerinde bulunan bir takım kuşatma planlarında temel mimari özelliklere dikkat edilmiş ancak dikkati dağıtacak detaylar eklenmemiştir. Pragmatik amacı olan bu tarz planların özenli yapılmakla beraber yalnızca şehrin ya da kalenin ana öğelerine değinmesi makuldür. Öte yandan gaza, sefer ve kuşatmaların tarihlerinden bahseden eserlerin resimlerinde hem estetik kaygı hem de, mesela 1566'da Sigetvar seferini anlatan Nüzhetü'l Esrār (Topkapı Sarayı Müzesi Kütüphanesi H. 1339) isimli eserde olduğu gibi, tarihsel gerçekliğe verilen dikkati görmek mümkündür. ${ }^{33}$ Benzer bir şekilde Berlin mecmuasında da bu dikkati görebiliriz. Ancak bu on yedinci yüzyıl ortasından olan resim, bir yüzyıl evvel başlayan geleneği devam ettirmekle beraber bakış açısını bir noktaya sabitlemesi açısından oldukça dikkat çekicidir. Yüksek bir noktadan, neredeyse tek bir bakış açışından kaleyi, nehri ve nehrin öte yakasını görürüz. Renk kullanımında ise açık yeşil, açık mavi ve gri tonları ile yer yer turuncular, onaltıncı yüzyıl resimli saray nüshalarında gördüğümüz can alıcı renk skalasına göre biraz daha soluktur, ancak belki de bu nedenle de esere daha da gerçekçi bir his katmıştır.

\section{Sonuç}

Bağdat kuşatmasının resmini kim yaptıysa çok özenli bir şekilde yaptığı aşikardır. Tüm mecmuada bu özeni görmek mümkündür. Mecmuanın organizasyonundan mizanpajına kadar, eserin son bölümünde bulunan metinleri destekleyen şemalara kadar her şey çok dikkatli bir şekilde hazırlanmıştır. Bu özeni Ahmed bin Musa'nın mecmuanın sonuna eklediği sebeb-i telif yazısı da destekler. Mecmua 1640-1642 yıllarında, yani Sultan İbrahim (h. 1640-1648) döneminde hazırlanmış olsa da, IV. Murad dönemine ve özellikle bu dönemde olan olaylara yer verilmiştir. ${ }^{34} \mathrm{Bu}$ detayları mecmuanın haşiye kısmına eklenen listelerde, tarihlerde ve metinlerde görmek mümkündür: Bağdat seferine katılan kişilerin isimleri, ölüm tarihleri (varak 379b, 380a), IV. Murad döneminde katledilen yeniçeri eşkiyaları (varak 375a), bu dönem Safevi elçisinden gelen hediyeler (varak 377a), sürülen ulema ve katledilen beyler (varak 378b) ve katledilen ulema (varak 379b) listelenmiştir. Ayrıca bu sultanın tahta geçişi (varak 174b, 365a) ${ }^{35}$ ve oğullarının doğum tarihleri (varak 367b) de belirtilmiştir. Bir bütün olarak incelendiğinde

32 Ahmet Karamustafa, Cartography in the Traditional Islamic and South Asian Societies, Volume 2, ed. J. B. Harley ve David Woodward (Chicago: University of Chicago Press, 1992), 209-227.

33 Bu konuda bkz. Şebnem Tamcan Parladır, "Sigetvarname Minyatürlerinde Metin-Resim İlişkisi," Filiz Çağman'a Armağan, haz. Ayşe Erdoğdu et al., (İstanbul: Lale Yayıncılık, 2018), 571-578.

34 Kafadar, "Sohbete Çelebi, Çelebiye Mecmûa," 50-51.

35 Burada Ahmed bin Musa, Nev 'i'nin eseri Netāyic-i Fünūn'a bir ara verir, eseri neredeyse güncelleyerek Nev'i'nin bıraktığı noktadan, yani II. Selim döneminden, Sultan İbrahim zamanına kadar kısa bir Osmanlı tarihi verir. Sonra Nev'i’nin eseri devam eder (varak 174v-175v). 
mecmua çeşit çeşit alanlarda, Kafadar'ın detaylı bir şekilde incelediği ve üzerinde çalışmaya devam ettiği "çelebi" okuyucuların bilmeye ihtiyacı olan eserleri ihtiva eder. ${ }^{36}$ Çoğunlukla onaltıncı ve onyedinci yüzyılda neşredilmiş Türkçe eserler ve Türkçe çevirileri kapsar. Özellikle de bu makalenin konusu olan resmin de dahil edilmesiyle dönemindeki pek çok mecmuadan ayırt edilir ve özellikle IV. Murad dönemine ve Bağdat'ın yeniden ele geçirilmesine verilen önemi de perçinler.

Teşekkür: Yorumları için Daria Kovaleva'ya, mecmuayı tanıttığı için Cemal Kafadar'a teşekkür ederim.

Hakem Değerlendirmesi: Dış bağımsız.

Çıkar Çatışması: Yazar çıkar çatışması bildirmemiştir.

Finansal Destek: Yazar bu çalışma için finansal destek almadığını beyan etmiştir.

Peer-review: Externally peer-reviewed.

Conflict of Interest: The author has no conflict of interest to declare.

Grant Support: The author declared that this study has received no financial support.

\section{Kaynakça/References}

Ambros, Edith. “An Ottoman Lațife of the $16^{\text {th }}$ Century." Osmanlı Araştırmaları 11 (1991): 25-34.

. "The Image in the $16^{\text {th }}$ Century of Representatives of Science and Technology: Cameos by the Ottoman Poet Fakîrî." Proceedings of the XIIth Congress of the Comité International d'Études PréOttomanes et Ottomanes. Archív Orientální, Prag 1996.

"The Letâif of Fakiri: Ottoman Poet of the $16^{\text {th }}$ Century." Wiener Zeitschrift für die Kunde des Morgenlandes 80 (1990): 59-78.

"Six Lampoons out of Fakîrî’s Risâle-i Ta rifât." Wiener Zeitschrift für die Kunde des Morgenlandes 82 (1992): 27-36.

Akdağ, Mustafa. Celali Isyanları (1550-1603). Ankara: Ankara Üniversitesi Basımevi, 1963.

Anonim, Baġdād seferinde sa 'adetlü pādişāhımızıñ iç og̉lanlarından bir iç og̉lanı merḥum ḳızlar ağasına irsal eyledügi mektub șuretidir, Britanya Kütüphanesi Add. 9704.

Bağcı, Serpil ve Filiz Çağman, Günsel Renda, Zeren Tanındı. Osmanlı Resim Sanatı. İstanbul: T.C. Kültür Bakanlığ1, 2006.

Çiçekler, Ahmet Naim ve Esma Baralı Çiçekler. "Berlin Devlet Kütüphanesinde Bulunan XVII. Yüzyıla Ait Bir Mecmuadaki Türk Atasözleri Derlemesi.” Dil ve Edebiyat Araştırmaları 18 (2018): 341-56.

Demirel, Şener. “16. Yüzyıl Divan Şairlerinden Tatavlalı Mahremî ve Şütürnâmesi.” Milli Folklor 9/5 (2005): 49-66.

Ebel, Katherine. "City Views, Imperial Visions: Cartography and the Visual Culture of Urban Space in the Ottoman Empire, 1453-1603.” Doktora Tezi, The University of Texas at Austin, 2002.

Haydar b. Abu'l Qāsım Aivaghli, Majma ' al-Inshả, Britanya Kütüphanesi Or. 3482.

İbrahim Peçevi. Peçevī Tārihi. İstanbul: Matbaa-i Amire, 1864.

36 Kafadar mecmualar ve çelebiler üzerine çalışmalarına devam etmekte ve bu konu hakkında bir kitap hazırlığındadır. Kafadar, "Sohbete Çelebi, Çelebiye Mecmûa," 49-51. 
Imber, Colin. "The Persecution of the Ottoman Shi' ites According to the Mühimme Defterleri, 1565-1585." Der Islam 2/56 (1979): 245-273.

Cemal Kafadar, "Sohbete Çelebi, Çelebiye Mecmûa," Mecmûa: Osmanlı Edebiyatının Kırkambarı, haz. Hatice Aynur, 45-52. İstanbul: Turkuaz Yayınları, 2012.

Karamustafa, Ahmet. "Military, Administrative, and Scholarly Maps and Plans." Cartography in the Traditional Islamic and South Asian Societies, Volume 2, Yayına hazırlayan J. B. Harley ve David Woodward, 209-227. Chicago: University of Chicago Press, 1992.

Köprülü, Mehmet Fuat. XVIIinci Asır Sazşairlerinden Kayıkçı Kul Mustafa ve Genç Osman Hikayesi. İstanbul: Evkaf Matbaası, 1930.

Küpeli, Özer. Osmanll-Safevi Münasebetleri (1612-1639). İstanbul: Yeditepe Yayınları, 2014.

Kütükoğlu, Bekir. Osmanl-Iran Siyasi Münasebetleri (1578-1612). İstanbul: İstanbul Fetih Cemiyeti, 1993. Murphy, Rhoads. Ottoman Warfare, 1500-1700. Londra: UCL Press, 1999.

Mușțafa b. Mulla Rı̣̣van el-Bag̉dādī, Tevārīh-i Fetihnnāme-i Bağdād be-dest-i Pādişāh-ı Dīn-penāh Sulțān Murād Hān Ġāzì, Oxford, Bodleian Kütüphanesi Or. 276.

Naima. Tarih-i Naima. Yayına hazırlayan Mehmet İpşirli. Ankara: Türk Tarih Kurumu Yayınları, 2007.

Naẓmīzāde Murtaża. Gülşen-i Hulefā: Bağdat Tarihi 762-1717. Yayına hazırlayan Mehmed Karataş. Ankara: Türk Tarih Kurumu Yayınları, 2014.

Pamuk, Şevket. "The Price Revolution in the Ottoman Empire Reconsidered." International Journal of Middle East Studies 33 (2001): 69-89.

Parladır, Şebnem T. "Sigetvarname Minyatürlerinde Metin-Resim İlişkisi.” Filiz Çağman'a Armağan. Yayına hazırlayan Lale Uluç, 571-578. İstanbul: Lale Yayıncılık, 2018.

Römer, Claudia. "Die Osmanische Belagerung Bagdads 1034-35/1624-25, Ein Augenzeugenbericht.” Der Islam 66 (1989): 119-136.

Roxburgh, David. "The Aesthetics of Aggregation: Persian Anthologies of the Fifteenth Century." Islamic Art and Literature. Hazırlayan Oleg Grabar ve Cynthia Robinson. (Princeton: Markus Wiener, 2001), 119-142.

Sahillioğlu, Halil. “Dördüncü Murad'ın Bağdad Seferi Menzilnamesi.” Belgeler, 2/3-4 (1965): 1-39.

Sefatgol, Mansur. "Majmū 'ah'hā: Important and unknown sources of historiography of Iran during the last Safavids the case of the Majmū 'ah-i Mìrzà Mu ìnā." Persian Documents: Social History of Iran in the Fifteenth to Nineteenth Centuries. Hazırlayan Nobuaki Kondo. (Londra: Routledge, 2003), 73-85.

Taner, Melis. "Caught in a Whirlwind: Painting in Ottoman Baghdad in the Late Sixteenth-Early Seventeenth Centuries.” Doktora Tezi, Harvard Üniversitesi, 2016.

Caught in a Whirlwind: A Cultural History of Ottoman Baghdad as Reflected in its Illustrated Manuscripts. Leiden: Brill, 2020.

Yıldırım, Nermin. “Karaçelebizade Abdülaziz Efendi'nin Zafername Adlı Eseri (Tarihçe-i Feth-i Revan ve Bağdad), Tahlil ve Metin.” Yüksek lisans tezi, Mimar Sinan Üniversitesi, 2005.

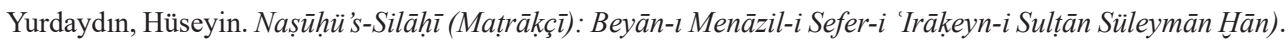
Ankara: Türk Tarih Kurumu Basımevi, 1976.

Zarain Aga, A Relation of the Late Seidge and Taking of the City of Babylon by the Turke, Londra, 1639. 


\section{Resimler}

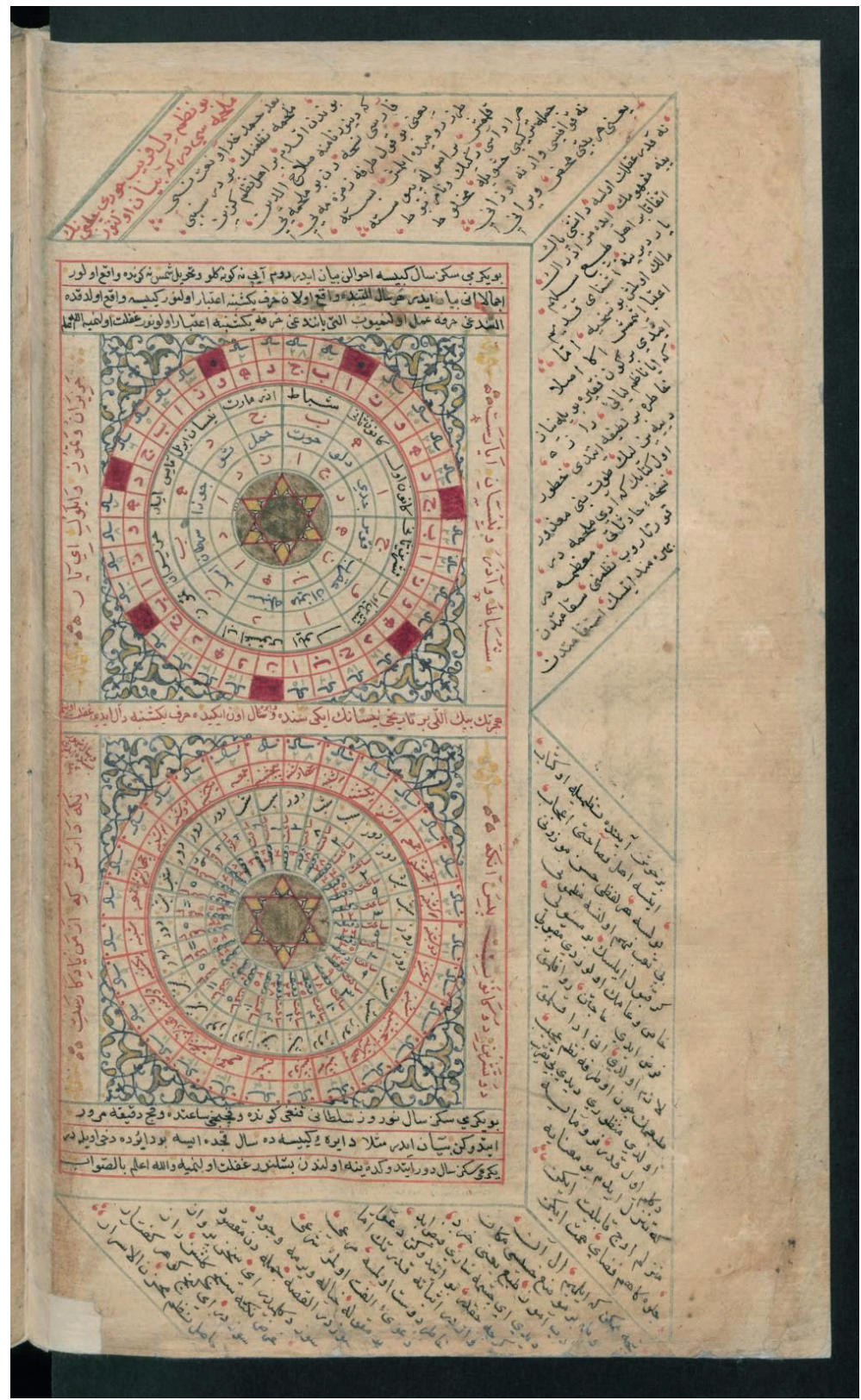

Resim 1: Sene-i kebise şeması, Mecmu ' $a$, Staatsbibliothek zu Berlin Or. Quart 1988, varak 432b 


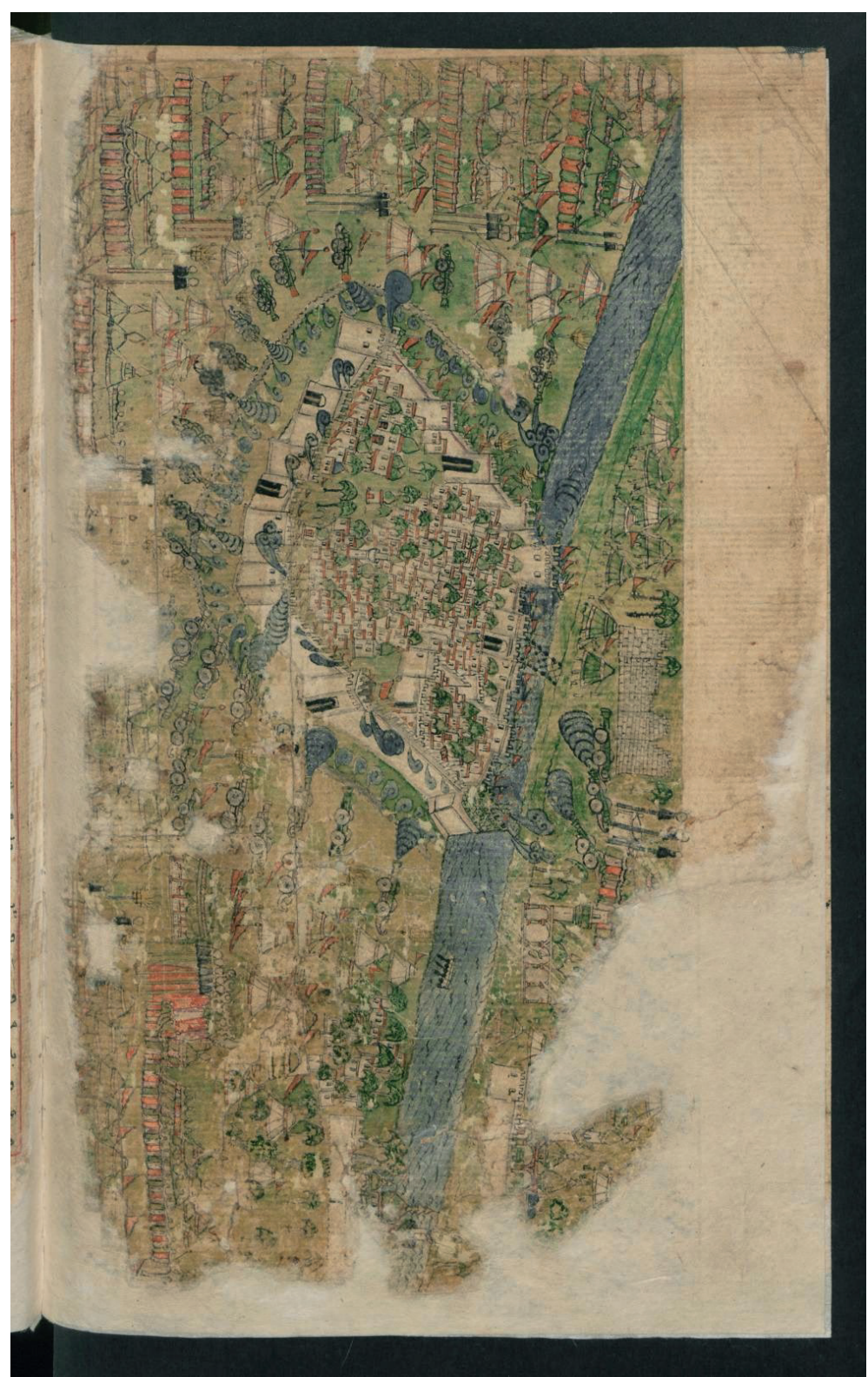

Resim 2: Bağdat Kuşatması, Mecmu 'a, Staatsbibliothek zu Berlin, Or. Quart 1988, varak 381b 


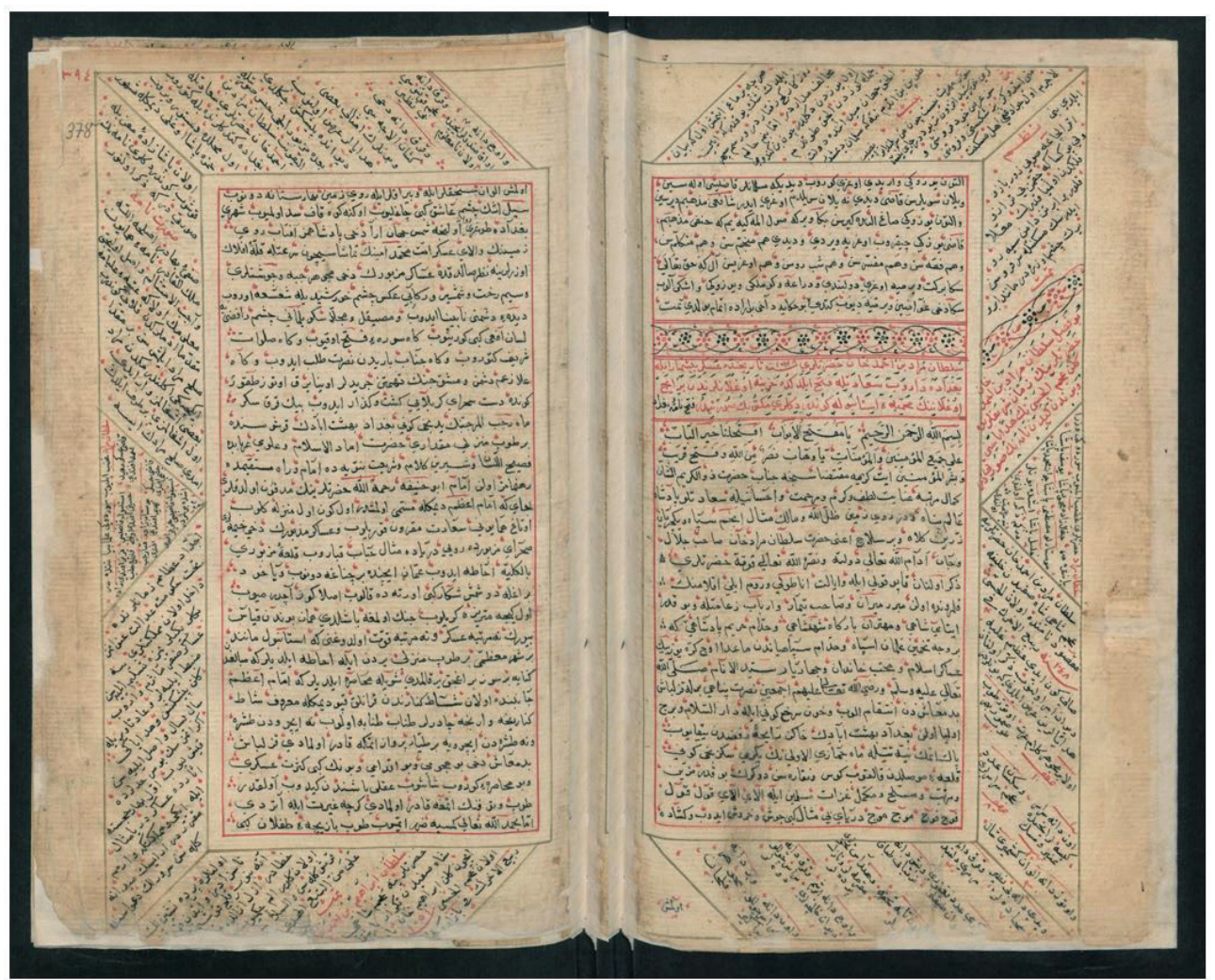

Resim 3: Bağdat kuşatması üzerine gönderilen mektubun başlangıcı (ana metin kısmında); Safevi elçisinden gelen hediyeler (haşiyede), Местu ' $a$, Staatsbibliothek zu Berlin, Or. Quart 1988, varak 377b-378a 


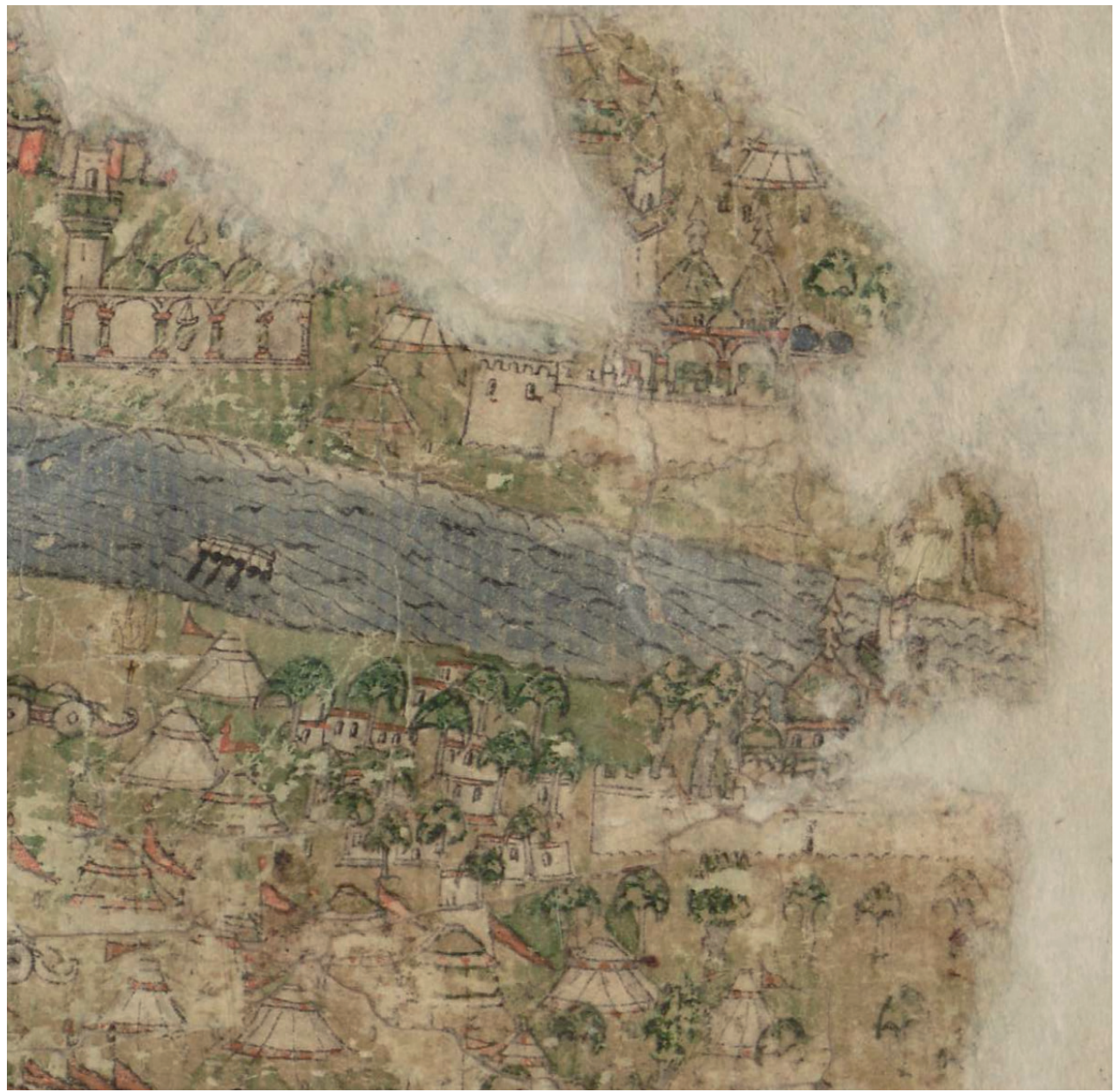

Resim 4: İmam-1 'Azam Ebu Hanife, İmam Musa el-Kazım, İmam Muhammed el-Cevad Türbeleri, Bağdat Kuşatması (detay), Мecmu ' $a$, Staatsbibliothek zu Berlin, Or. Quart 1988, varak 381b 
